\title{
Synthesis of New Antibiotics via Mannish Reaction
}

\author{
Purti Bilgaiyan* \\ Department of Chemistry, Sagar Institute of Research and Technology, India
}

*Corresponding author: Purti Bilgaiyan, Department of Chemistry, Sagar Institute of Research and Technology, Indore, Madhya Pradesh, India.

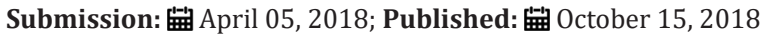

\section{Introduction}

Development of efficient and environmentally friendly chemical process for preparation of new biologically active molecules constitutes a major assignment for chemists in organic synthesis. Therapeutic drugs have played a major role in increasing average life. For a long time, natural sources have been used to prepare medicines for treatment of human ailments. Many new medicines actually are modified version of old medicines that have been improved to help people feel better [1]. A variety of medicinal agents have symbolic qualities and better results with numerous reactions for providing new chemical entities. Among well-known reactions, Mannich reaction has been of great importance due to its diversified applications-especially in medicinal chemistry. Mannich reaction is a condensation process involving three reactants (substrate, aldehyde and amine). Mannich reaction is considered only in general way here. Pathway a or b (Figure 1) can be followed, if one includes a rather unlikely trimolecular mechanism. In case formaldehyde reacts initially with the amine (Path 'a'), a condensation product having the structure of $x$-amino methyl derivative or methylene immonium salt is formed, which is then able to attack the substrate RH. Alternatively (Path ' $b$ '), a hydroxymethyl derivative is generated, which gives the Mannich Base by reaction with imine $[2,3]$.

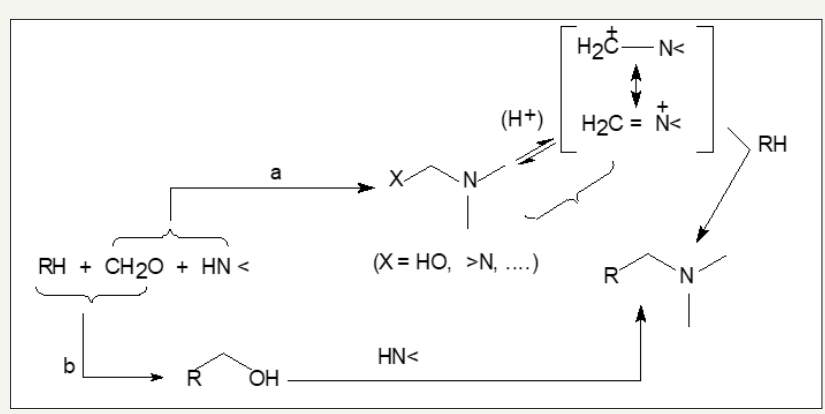

Figure 1: Mechanistic routes of Mannich reaction.

\section{Synthesis of Mannich Bases}

\section{Synthesis of mannich bases from primary amines}

Mannich Bases were prepared by reacting amide $(0.01 \mathrm{~mol})$ dissolved in $20 \mathrm{ml}$ of ethanol with sulphonamide $(0.01 \mathrm{~mol}) .2 .5 \mathrm{~mL}$
$(0.01 \mathrm{~mol})$ of formaldehyde solution $(37 \%, \mathrm{v} / \mathrm{v})$ was added slowly with constant stirring. The $\mathrm{pH}$ of the mixture was adjusted to 3.5 by adding $0.5 \mathrm{~mL}$ of $1 \mathrm{~mol} \mathrm{~L}^{-1} \mathrm{HCl}$. The mixture was kept at efficient ice cooling for half an hour and refluxed on water bath. Reflux time varied with the sulphonamide used. The refluxed mixture was kept at $0{ }^{\circ} \mathrm{C}$ for four days when crystalline product was obtained. The product was recrystallized from DMF [4].

\section{Synthesis of mannich bases from secondary amines}

Secondary amine $(0.01 \mathrm{~mol})$ was added to an ethanolic solution $(50 \mathrm{ml})$ of Active hydrogen compound $(0.01 \mathrm{~mol})$ in a flat bottom flask. Amount of $0.4 \mathrm{~mL}(0.015 \mathrm{~mol})$ of formaldehyde solution $(37 \%, \mathrm{v} / \mathrm{v})$ was added slowly with constant stirring. The reaction mixture was stirred at $70-75^{\circ} \mathrm{C}$ for 3 to 8.5 hours, depending upon the secondary amine [5]. The remaining portion of formaldehyde solution was added in two installments after 1 and 2 hours, respectively. The reaction mixture was kept overnight in the refrigerator. Next day, the excess of solvent was distilled off from the reaction mixture under reduced pressure. It was again kept for crystallization in the refrigerator. The product obtained was purified by recrystallization from DMF. Mannich Bases have been synthesized from various substrates by modifying them using Mannich reaction. It involves the reaction of active hydrogen component, formaldehyde and amine (sulphonamide/secondary amine). The structure of the newly synthesized Mannich Bases has been elucidated by physicochemical methods and spectral techniques.

we can synthesize Mannich Base through condensation of some aromatic and heterocyclic compounds with sulphonamides and various secondary amines [6]. They were screened for their antibacterial properties. The antibacterial activities of Mannich Bases were tested against some pathogenic bacteria as follows:

Gram positive: Bacillus subtilis (B. subtilis)

Staphylococcus aureus (S. aureus).

Gram negative: Escherichia coli (E. coli)

Salmonella typhosa (S. typhosa)

Pseudomonas aeruginosa (P. aeruginosa)

Klebsiella pneumoniae (K. pneumoniae). 
The investigation of sensitivity of bacteria to antibacterial agents is usually done by various methods with their advantages and limitations for screening antibacterial properties. We have studied these properties by cup plate method.

\section{Innovation of New Drugs via Mannich Reaction}

Mannich reaction has been used as an important tool for several years to acquire compounds with several pharmacological properties. Rapid expansion of investigations in this field is largely due to increasing utility on these compounds. Mannich Bases are synthesized by condensation of active hydrogen compounds with formaldehyde and primary and/or secondary amines. Mannich Bases synthesized from different active hydrogen compounds, which have great medicinal importance. The Mannich bases incorporated with sulphonamides are reported to be potent antibacterial agents and less toxic than parent sulphonamide. Different active hydrogen compound used as a substrate and sulphonamide as amine component were condensed via Mannich reaction. A series of Mannich bases were synthesized with different sulphonamides/ secondary amines. The synthesized Mannich Bases appear to be better and more potent antibacterial agents than sulphonamides themselves. These results warrant detailed pharmacological studies of these Mannich Bases [7]. Mannich Bases are not only important in research, but they also have considerable practical use in a wide range of other fields. Moreover, these compounds are equally important in pharmacology. This research is expected to facilitate the pharmaceutical industry in the good cause of manufacturing medicines with low cost and minimum side effects. Overall, I want synthesized series of new drugs which is more effective for diseases and less side effect on human body and also available in very low cost in the market, so I can help to the society in these ways.

\section{References}

1. Tramontini M, Angiolini L (1990) Further advances in the chemistry of Mannich bases. Tetrahedron 46(6): 1791-1837.

2. Tramontini M, Angiolini L (1994) Mannich base: Chemistry and uses. CRC Press, Boca Raton, Florida, USA, pp. 7-20.

3. Joshi S, Khosla N, Tiwari P (2004) In vitro study of some medicinally important Mannich bases derived from anti-tubercular agent. Bioorganic and Medicinal Chemistry 12(3): 571-576.

4. Joshi S, Manikpuri A, Tiwari P (2007) Synthesis and biological study of medicinally important Mannich bases derived from 4-(dimethylamino)1,4,4a,5,5a,6,11,12a-octahydro-3,6,10,12,12a pentahydroxy naphthacene carboxamide. Bioorg Med Chem Lett 17(3): 645-648.

5. Joshi S, Bilgayan P, Pathak A (2012) J Chil Chem Soc 58(3).

6. Mandloi D, Joshi S, Khadikar PV, Khosla N (2005) QSAR study on the antibacterial activity of some sulfa drugs: building blockers of Mannich bases. Bioorg Med Chem Lett 15(2): 405-411.

7. Joshi S, Bilgaiyan P, Pathak A (2017) Synthesis, spectroscopic characterization and antibacterial screening of novel Mannich bases of Ganciclovir. Arabian J of chemistry 10(1): S1180-S1187.
Creative Commons Attribution 4.0

International License

For possible submissions Click Here

\section{Submit Article}

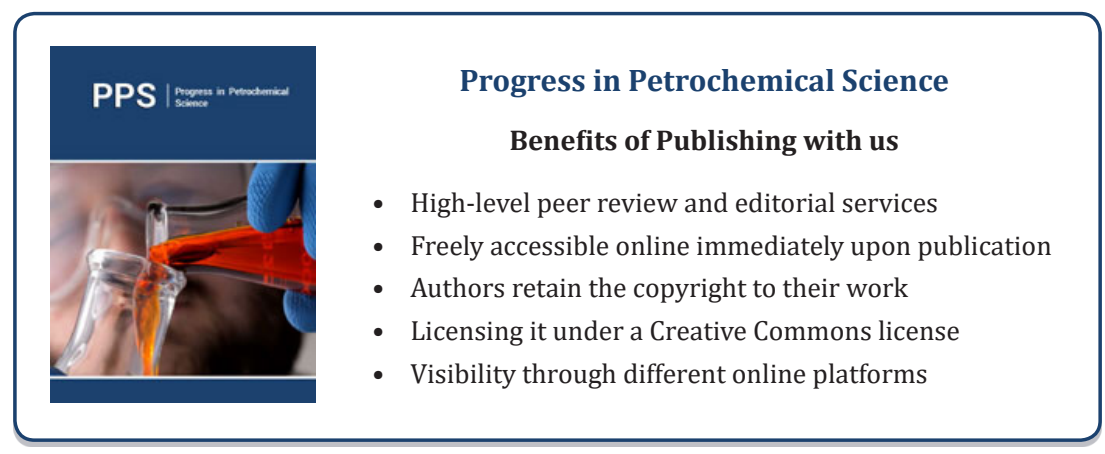

